\title{
Christine Pigné, Ronsard, le sang et les images
}

\section{Filippo Fonio}

\section{(2) OpenEdition}

\section{Journals}

\section{Edizione digitale}

URL: http://journals.openedition.org/studifrancesi/30066

DOI: 10.4000/studifrancesi.30066

ISSN: 2427-5856

\section{Editore}

Rosenberg \& Sellier

\section{Edizione cartacea}

Data di pubblicazione: 1 avril 2006

Paginazione: 141

ISSN: 0039-2944

\section{Notizia bibliografica digitale}

Filippo Fonio, «Christine Pigné, Ronsard, le sang et les images», Studi Francesi [Online], 148 (XLX | I) | 2006, online dal 30 novembre 2015, consultato il 19 avril 2021. URL: http://journals.openedition.org/ studifrancesi/30066 ; DOI: https://doi.org/10.4000/studifrancesi.30066

\section{Questo documento è stato generato automaticamente il 19 avril 2021.}

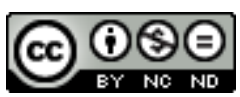

Studi Francesi è distribuita con Licenza Creative Commons Attribuzione - Non commerciale - Non opere derivate 4.0 Internazionale. 


\title{
Christine Pigné, Ronsard, le sang et les images
}

\author{
Filippo Fonio
}

\section{NOTIZIA}

CHRISTINE PIGNÉ, Ronsard, le sang et les images, «Bibliothèque d'Humanisme et

Renaissance», LXVII, 1 (2005), pp. 47-78.

1 La studiosa propone un contributo su una base semantica e filologicamente fondata, offrendo un'interpretazione del motivo ematico nelle opere del poeta a partire dalle occorrenze del termine sang nella lirica ronsardiana. La fisiologia del sangue riveste un'importanza tutta particolare per Ronsard, importanza che anzi tende a crescere con la maturità del poeta. Il motivo ematico in Ronsard va anche al di là della sfera erotica stricto sensu, dell'eredità petrarchesca neoplatonizzante, ferma restando l'influenza degli scritti di Ficino ai fini della riflessione ronsardiana sulla tematica del sanguis. Il sangue è per Ronsard sede dell'immaginazione, della fantaisie, copula, elemento che permette la trasmissione all'anima, immateriale, delle impressioni raccolte dagli organi di senso. Si tratta di un forte valore gnoseologico attribuito al sangue, come tramite e come bacino dal quale attingere impressioni e immagini in absentia degli oggetti da cui esse sono scaturite. Alla messa a fuoco di una tale prospettiva contribuiscono retaggi dell'Antichità, come la teoria umorale del sangue, quella della predominanza di una componente del sangue per ciascuna delle età dell'uomo, quella già aristotelica del potere generativo del sangue. Ronsard reinterpreta tali acquisizioni sulla base della propria riflessione e sensibilità poetica, nella quale in particolare si assiste a uno stretto connubio fra la matrice profana del sangue e il motivo, altrettanto diffuso, del sangue di Cristo. 